\title{
Lawsone: A novel reagent for the detection of latent fingermarks on paper surfaces
}

\author{
Renee Jelly, ${ }^{a}$ Simon W. Lewis, ${ }^{* a}$ Chris Lennard, ${ }^{b}$ Kieran F. Lim ${ }^{c \S}$ and Joseph Almog ${ }^{d}$ \\ Received (in XXX, XXX) 1st January 2007, Accepted 1st January 2007 \\ First published on the web 1st January 2007 \\ DOI: $10.1039 / b 000000 x$
}

\begin{abstract}
${ }_{5}$ Lawsone (2-hydroxy-1,4-naphthoquinone) reacts with latent fingermark deposits on paper surfaces to yield purple-brown impressions of ridge details which are also photoluminescent; this compound represents the first in a completely new class of fingermark detection reagents.
\end{abstract}

${ }_{10}$ Fingermarks remain the most widely used and reliable means of personal identification and, hence, are extremely important to law enforcement as contact evidence. ${ }^{1}$ A key element in the successful recovery of a latent (invisible) fingermark from a scene or object is detection; to this end, a range of physical 15 and chemical methods are available for the visualization of such fingermarks. ${ }^{1,2}$

Amino acids are a key component of the secretions that contribute to latent fingermarks ${ }^{3}$ and are particularly important when porous surfaces, such as paper, are examined, 20 as they tend to bond to paper fibres and are thus long-lived. ${ }^{2}$ Ninhydrin (2,2-dihydroxy-1,3-indanedione) was the first amino acid sensitive reagent for developing fingermarks on porous surfaces and is still the most widely used. Ninhydrin reacts with amino acids to form a dark purple coloured ${ }_{25}$ compound known as Ruhemann's purple (Scheme 1). ${ }^{2}$<smiles>[R4]c1ccc2c(c1)C(=O)C(O)(O)C2=O</smiles>

Scheme 1 Reaction of ninhydrin with amino acids

These treated impressions may be further enhanced by treatment with zinc and cadmium salts to produce complexes 30 that exhibit photoluminescence when cooled to liquid nitrogen temperature $\left(-196^{\circ} \mathrm{C}\right)$ and excited with high intensity light sources. ${ }^{2}$

Since the early 1980 's, a range of ninhydrin analogues have been synthesized and tested for their suitability as reagents for 35 the detection of latent fingermarks. Despite the large body of work carried out, only two such reagents have found widespread operational use: 1,8-diazafluoren-9-one (DFO) and 1,2-indanedione. ${ }^{1,2}{ }^{4}$ (Fig. 1) More recently, Almog and co-workers have suggested the natural product genipin as an 40 operationally safer and environmentally benign fingermark reagent exhibiting both colour and photoluminescence. ${ }^{5,6}$

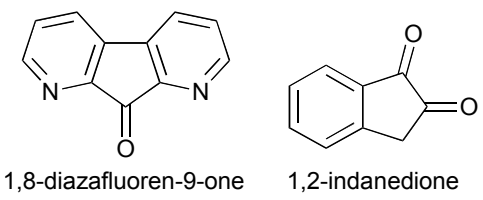

Fig. 1 Amino acid targeting reagents for the development of latent fingermarks

Traditionally genipin has been used as a fabric and skin dye, and this led us to investigate the potential of other natural products, which have been used in this fashion, as fingermark reagents. Henna, a natural product sourced from the leaves of so Lawsonia inermis, in a similar manner to genipin, has been used as a skin and hair dye for millennia with reports of its use dating back to 1,400 BC. ${ }^{7}$ Lawsone (2-hydroxy-1,4naphthoquinone, Fig. 2) is the compound thought to be responsible for the staining properties of henna. ${ }^{7}$ This 55 compound was thus selected to be investigated for its ability to develop latent fingermarks on paper surfaces.<smiles>O=C1C=C(O)C(=O)c2ccccc21</smiles>

Fig.2 Chemical structure of lawsone

Lawsone is a naphthoquinone, a group of compounds that 60 are well known for their reactions with amino acids. 1,2Naphthoquinone-4-sulfonate has been applied to the determination of amino acids through the formation of highly coloured compounds ${ }^{8-10}$ and 1,2-naphthoquinone has been reported as yielding brown/purple pigments with cysteine and ${ }_{65}$ proteins. ${ }^{11}$ Spectroscopic evidence indicates that the reaction of 1,2-naphthoquinone occurs as a result of the primary amine component of amino acids. ${ }^{11}$ Intriguingly, a paper describing investigations into the reactivity of the phenyliodonium ylide of 2-hydroxy-1,4-naphthoquinone with amino compounds, 70 suggests the formation of indanedione-2-carboxamido compounds, ${ }^{12}$ thus offering an alternative window on the reaction mechanism of 1,2-indanedione. ${ }^{13}$ Naphthoquinones therefore represent a class of compounds of significant interest as potential fingermark detection reagents.

75 Latent fingermarks were collected on filter paper from a number of different volunteers. Volunteers were requested not to wash their hands immediately before collecting impressions; the fingers were not "charged" with additional 
secretions in any way. The filter paper strips were then dipped in the lawsone reagent solution, air dried and then heated, either in an oven or by direct heat using a laundry press. Initial experiments with lawsone in ethanolic solution yielded 5 purple/brown developed marks, which also exhibited strong photoluminescence when illuminated with a forensic light source (Polilight PL500, Rofin, Australia) at $555 \mathrm{~nm}$ and viewed through red goggles. (Figure 3)

(a)

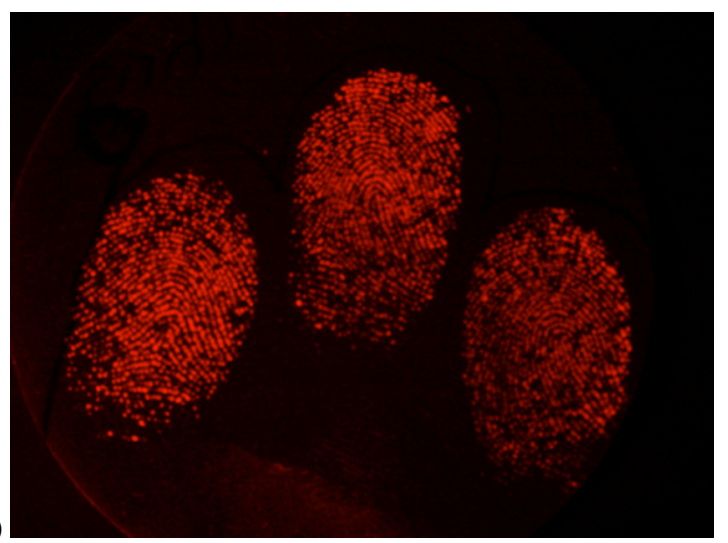

(b)

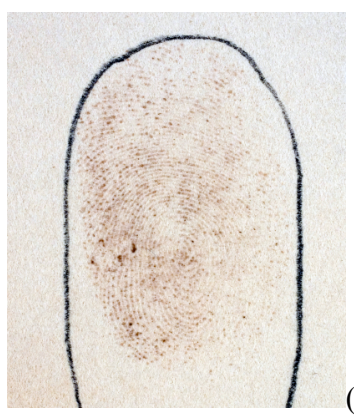

c)

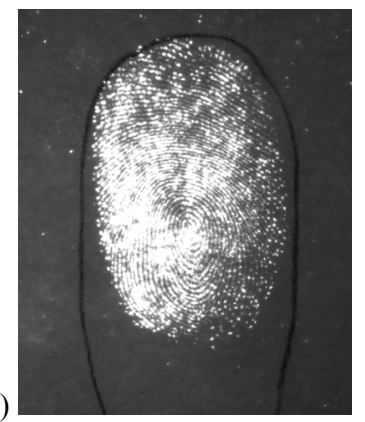

Fig.3 . Lawsone treated latent fingermarks Images (a) and (b) were taken with a Pentax K10 digital SLR, $50 \mathrm{~mm}$ focal length, ISO 100. (a) photoluminescence mode (excitation with a Polilight PL 500 at $590 \mathrm{~nm}$ 15 and viewed through a Wratten NA29 filter, shutter speed $6.0 \mathrm{~s}$, aperture f2.8). (b) taken under white light (shutter speed 1/125 s, aperture f4), (c) acquired using a Poliview digital imaging system (Rofin, Australia) with excitation at $590 \mathrm{~nm}$, viewed through a $650 \mathrm{~nm}$ interference filter with a $1 \mathrm{~s}$ exposure time:

20 The photoluminescence was further investigated using a Cary Fluorescence Spectrophotometer (Varian, Mulgrave, Australia) with a Fibre Optic Probe attachment (Varian, Mulgrave, Australia), and it was determined that the maximum intensity of luminescence occurred at around 640 $25 \mathrm{~nm}$ with excitation at $590 \mathrm{~nm}$. This is operationally significant as photoluminescence emission at longer wavelengths has the potential to improve detectability by avoiding native background luminescence.

It was found that using ethanol as a carrier solvent lead to a 30 significant discolouration of the paper substrate, resulting in a degradation of image quality. Ethanol would be unsuitable as a carrier solvent for operational use due to its polarity, which would cause problems with written document evidence due to ink diffusion through the paper. We investigated methyl ${ }_{35}$ nonafluoroisobutyl ether (HFE-7100) as the carrier solvent for the working solution; this solvent is used widely for fingermark reagents such as 1,2-indanedione. ${ }^{2}$ In order to successfully dissolve lawsone, a co-solvent of higher polarity was required. Ethyl acetate $(20 \%)$ was found to be the most 40 successful of the solvents investigated. We also found that petroleum spirit $60-80^{\circ} \mathrm{C}$ could substitute for HFE-7100 without a serious impact on the quality of the developed fingermarks.

Preliminary studies established that a concentration of 1 $45 \mathrm{mg}$ lawsone $/ \mathrm{mL}$ gave the best compromise between contrast and background interference. with excess concentrations leading to discolouration of the paper substrate. The formulation used for the remainder of the study was prepared in the following fashion: lawsone $(50 \mathrm{mg}$; Sigma-Aldrich) was ${ }_{50}$ dissolved in ethyl acetate $(10 \mathrm{~mL}$; Univar) and the resulting solution was subsequently mixed with HFE-7100 (40 mL; 3M Novec). Latent fingermark samples on filter paper were dipped in this solution, air dried and then developed with heat. Heating in an oven for 1 hour at $140^{\circ}-170 \mathrm{C}$ produced more 55 uniform development than heating with a laundry press, providing enhancement sufficient for complete visualisation of fingermark ridge details.

In order to verify that lawsone was reacting with the amino acid content of the latent fingermarks, solution of amino acids 60 in water (lysine, alanine, glycine, proline; all at $900 \mu \mathrm{g} / \mathrm{mL}$ ) were dispensed $(10 \mu \mathrm{L})$ onto filter paper and allowed to air dry before subsequent lawsone treatment. In common with the developed latent fingermarks, the amino acid spots with the exception of proline developed as purple/brown stains which

${ }_{65}$ were also photoluminescent. Fluorescence spectra of the developed amino acid spots and a developed latent fingermark are presented in Fig. 4. It is clear from the profiles that the photoluminescent characteristics of the product of the reaction between primary amino acids and lawsone are similar to that 70 in lawsone developed fingermarks, thus confirming that the lawsone reagent is non-specifically targeting primary amino acids in the latent fingermark deposit. This is a key requirement of latent fingermark reagents, as the amino acid content of natural secretions is highly variable from one 75 subject to another. ${ }^{3}$

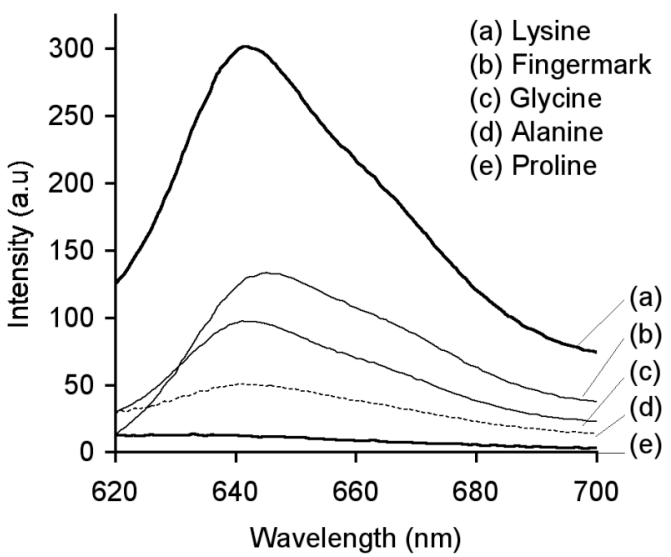

Fig.4 Fluorescence spectra of a lawsone developed latent fingermark and of selected amino acids on filter paper (excitation wavelength $590 \mathrm{~nm}$ ) 
Lawsone can undergo keto-enol tautomerisation as shown in Scheme 2. Spartan '04 ${ }^{14}$ ab initio calculations using HF/6 $31 \mathrm{G}^{*}$ theory that indicate that the 1-position of all 6 species/conformers is most likely to react with an incoming 5 nucleophile.

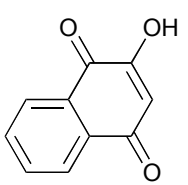

2-hydroxy-1,4-naphthoquinone (lawsone) 2 conformers

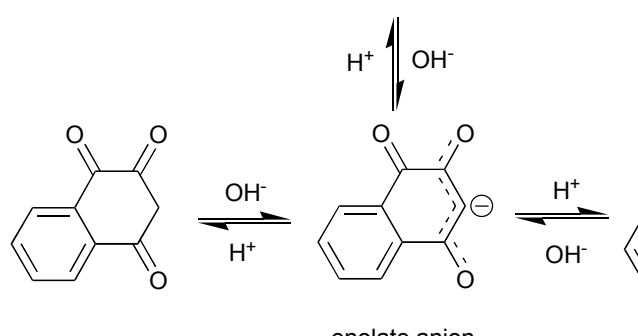

enolate anion

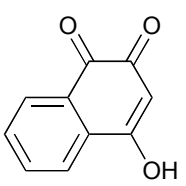

2 conformers

Scheme 2 Lawsone and isomers

Based on the known reactivity of hydroxyquinones ${ }^{15}$ and ninhydrin ${ }^{16}$, we postulate that lawsone undergoes a Strecker ${ }_{10}$ degradation ${ }^{17}$ at the 1-position to form the amine intermediate (I), as shown in Scheme 3. The Strecker degradation requires a primary amino $\operatorname{acid}^{17}$, which would explain why proline does not form the fluorescent product. The amine (I), is a nucleophilic base which can react with a second lawsone ${ }_{15}$ molecule to reduce the ketone at the 1 '-position ${ }^{18}$ to form the final product, in which the negative charge can be delocalised over the extended $\pi$-system.

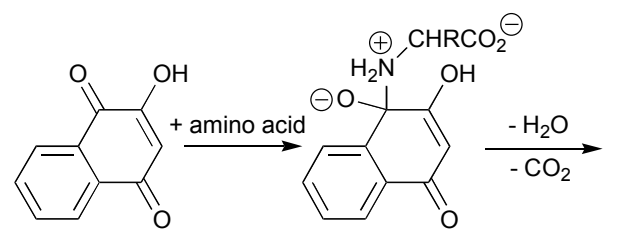

lawsone
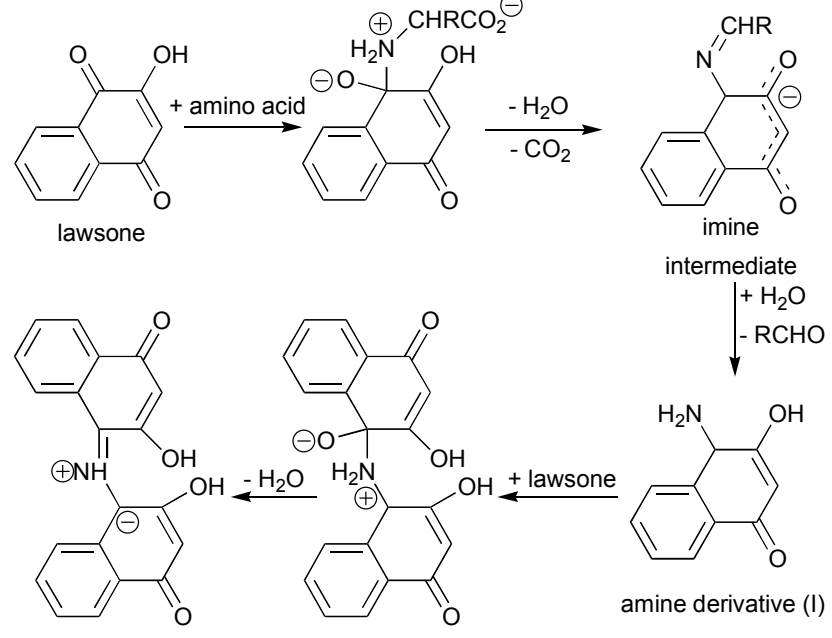

amine derivative (I)

20

Scheme 3 Proposed reaction pathway and product for the reaction of lawsone with primary amino acids

Further research is required to investigate the reaction mechanism involved and optimise the development conditions for this fingermark detection reagent. In addition, there is the potential that lawsone could find wider application as a 25 fluorogenic reagent for amino acids; however, additional studies are required to determine optimum reaction conditions in solution and sensitivity versus existing reagents.

This work was supported by a Curtin Linkage Grant in collaboration with the Australian Federal Police, Forensic ${ }_{30}$ Science South Australia, and the Western Australia Police. RJ was supported by a Curtin University Postgraduate Scholarship The authors wish to thank Dr Steve Gutowski (Victoria Police Forensic Services Department) for useful discussions relating to this research, Glen Lawson (Applied ${ }_{35}$ Physics, Curtin University of Technology) for assistance with photography and Emma Patton (Applied Chemistry, Curtin University of Technology) for comments on the draft manuscript.

\section{Notes and references}

${ }_{40}{ }^{a}$ Department of Applied Chemistry, Curtin University of Technology, GPO Box U1987, Perth, Western Australia 6845, Australia. Fax: 618 9266 2300; Tel: 6189266 2484; E-mail: S.Lewis@curtin.edu.au

${ }^{b}$ National Centre for Forensic Studies, Faculty of Science, University of Canberra, Canberra, ACT 2601, Australia.

${ }_{45}{ }^{c}$ School of Life and Environmental Sciences, Deakin University, Geelong, Victoria 3217, Australia.

${ }^{d}$ Casali Institute of Applied Chemistry, Hebrew University, Jerusalem 91904, Israel.

$\S$ Lim Pak Kwan (林百君)

50 1. J. Almog, in Encyclopedia of Forensic Sciences, eds. J. Siegel, P. Saukko and G. Knupfer, Academic Press, San Diego, Editon edn., 2000, vol. 2, pp. 890-900.

2. C. Champod, C. Lennard, P. Margot and M. Stoilovic, Fingerprints and Other Ridge Skin Impressions, CRC Press, Boca Raton, 2004.

55 3. S. Bramble and J. Brennan, in Encyclopedia of Forensic Sciences, eds. J. Siegel, P. Saukko and G. Knupfer, Academic Press, San Diego, Editon edn., 2000, vol. 2, pp. 862-869.

4. D. B. Hansen and M. M. Joullié, Chem. Soc. Rev., 2005, 34, 408-417.

5. J. Almog, Y. Cohen, M. Azoury and T.-R. Hahn, J. Forensic Sci., $602004,49,255-258$.

6. G. Levinton-Shamuilov, Y. Cohen, M. Azoury, A. Chaikovsky and J. Almog, J. Forensic Sci., 2005, 50, 1367-1371.

7. R. Petkewich, Chemical and Engineering News, 2006, 84, 28.

8. E. Frame, J. Russell and A. Wilhelmi, J. Biol. Chem., 1943, 149, 255270.

9. N. H. Furman, G. H. Morrison and A. F. Wagner, Anal. Chem., 1950, 22, 1561-1562.

10. J. Saurina, S. Hernandez-Cassou and R. Tauler, Anal. Chem., 1995, 67, 3722-3726.

70 11. J. R. Rees and A. Pirie, Biochem. J., 1967, 102, 853-863.

12. K. Spagou, E. Malamidou-Xenikaki and S. Spyroudis, Molecules, 2005, 10, 226-237.

13. O. Petrovskaia, B. M. Taylor, D. B. Hauze, P. J. Carroll and M. M. Joullié, J. Org. Chem., 2001, 66, 7666-7675.

75 14. Spartan '04, Program is available from Wavefunction, Inc.,18401 Von Karman Avenue, Suite. 370, Irvine, CA 92612, USA $<$ http://www.wavefun.com>, 2004.

15. S. Spyroudis, Molecules, 2000, 5, 1291-1330.

16. D. McCaldin, Chemical Reviews, 1960, 60, 39-51.

80 17. A. Schonberg and R. Moubacher, Chemical Reviews, 1952, 50, 261277.

18. J. McMurry, Organic Chemistry, 6th edn., Brookes/Cole, Pacific Grove (CA), 2004. 